\title{
Author Correction: Selection of DNA Aptamers for Differentiation of Human Adipose-Derived Mesenchymal Stem Cells from Fibroblasts
}

\author{
Mariane Izabella Abreu de Melo ${ }^{1,2}$ (D) Pricila da Silva Cunha ${ }^{1,2}$ (D) \\ Marcelo Coutinho de Miranda ${ }^{1}$ (D) . Joana Lobato Barbosa ${ }^{1}$ (D). \\ Jerusa Araújo Quintão Arantes Faria ${ }^{3}$ (D) . Michele Angela Rodrigues ${ }^{4}(\mathbb{D}$. \\ Alfredo Miranda de Goes ${ }^{1}$ D . Dawidson Assis Gomes ${ }^{1}$ (D) \\ Published online: 7 October 2021 \\ (c) Springer Science+Business Media, LLC, part of Springer Nature 2021
}

\section{Author Correction: Applied Biochemistry and Biotechnology https://doi.org/10.1007/s12010-021-03618-5}

The original version of this article unfortunately contained a mistake in the supplementary files and Figure 1. The correct supplementary files and Figure 1 are shown here.

The original article has been corrected.

The original article can be found online at https://doi.org/10.1007/s12010-021-03618-5.

Mariane Izabella Abreu de Melo

abreu.mariane@gmail.com

$\triangle$ Pricila da Silva Cunha pribqi@gmail.com

1 Departamento de Bioquímica e Imunologia, Instituto de Ciências Biológicas, Universidade Federal de Minas Gerais, Belo Horizonte 31270-901, Brazil

2 Present Address: Centro de Desenvolvimento da Tecnologia Nuclear, Comissão Nacional de Energia Nuclear, Av. Antônio Carlos, 6627, Horizonte, Belo 31270-901, Brazil

3 Departamento de Ciências Fisiológicas, Instituto de Ciências Biológicas, Universidade Federal do Amazonas, Manaus 69080-900, Brazil

4 Departamento de Patologia Geral, Instituto de Ciências Biológicas, Universidade Federal de Minas Gerais, Belo Horizonte 31270-901, Brazil 
a Apta 2

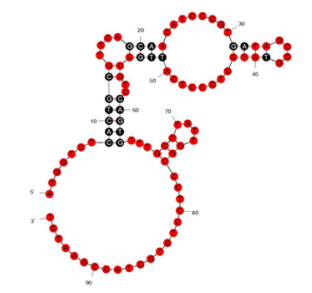

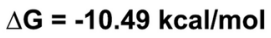

C Apta 42

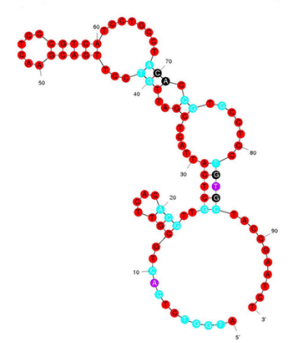

$\Delta \mathbf{G}=-9.00 \mathrm{kcal} / \mathrm{mol}$ b Apta 21

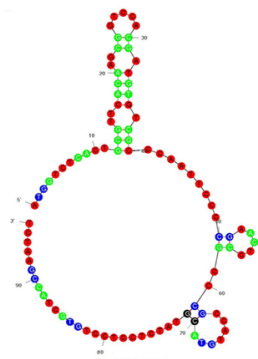

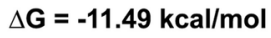

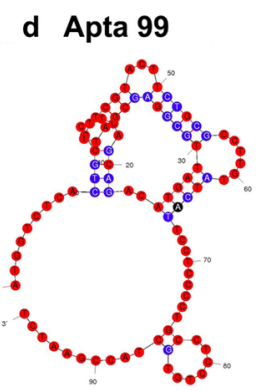

$\Delta G=-12.71 \mathrm{kcal} / \mathrm{mol}$ e Scrambled

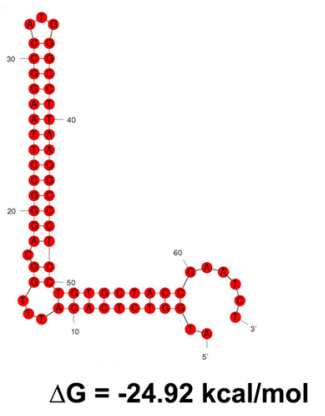

Supplementary figure 1 

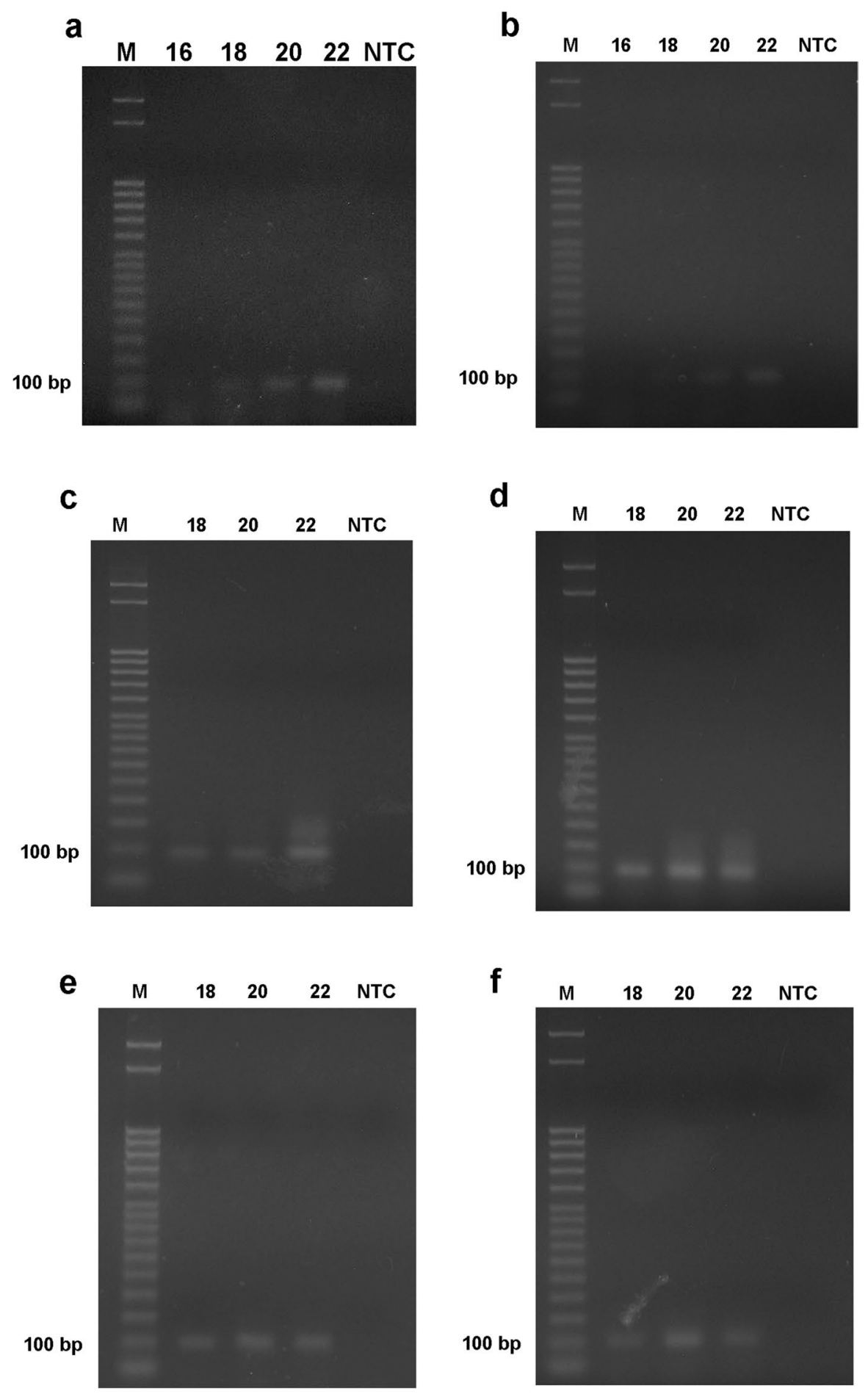

Supplementary figure 2 
a

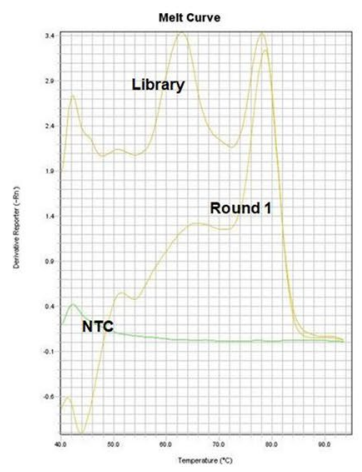

d

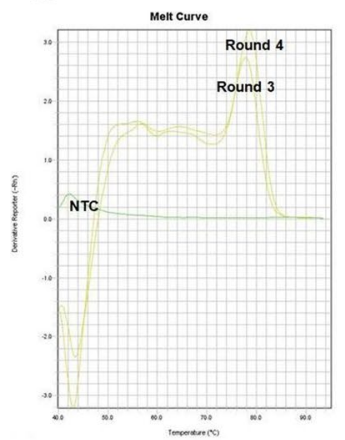

g

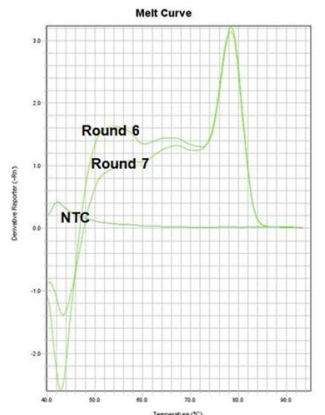

b

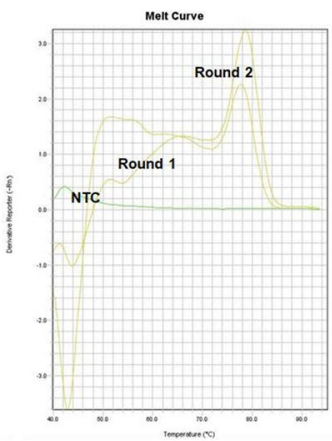

e

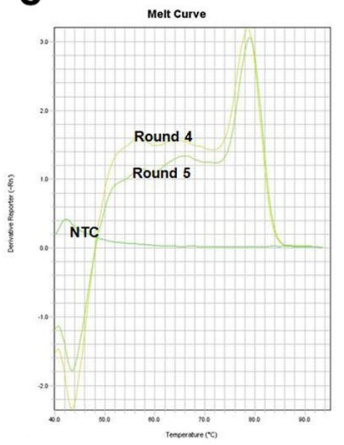

h

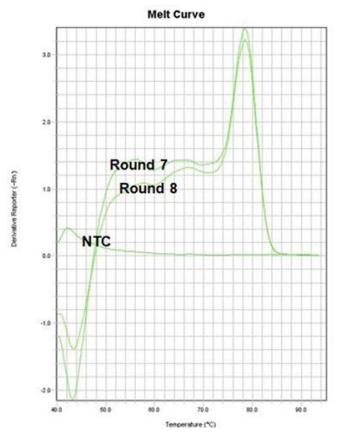

C

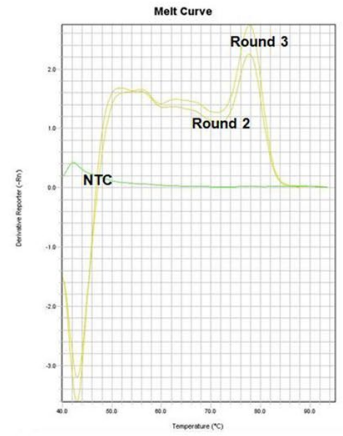

f

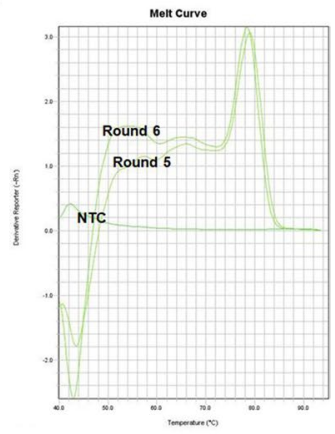

i

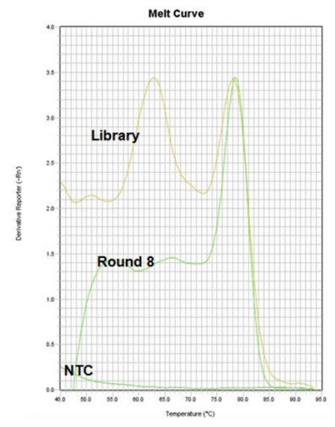

Supplementary figure 3 


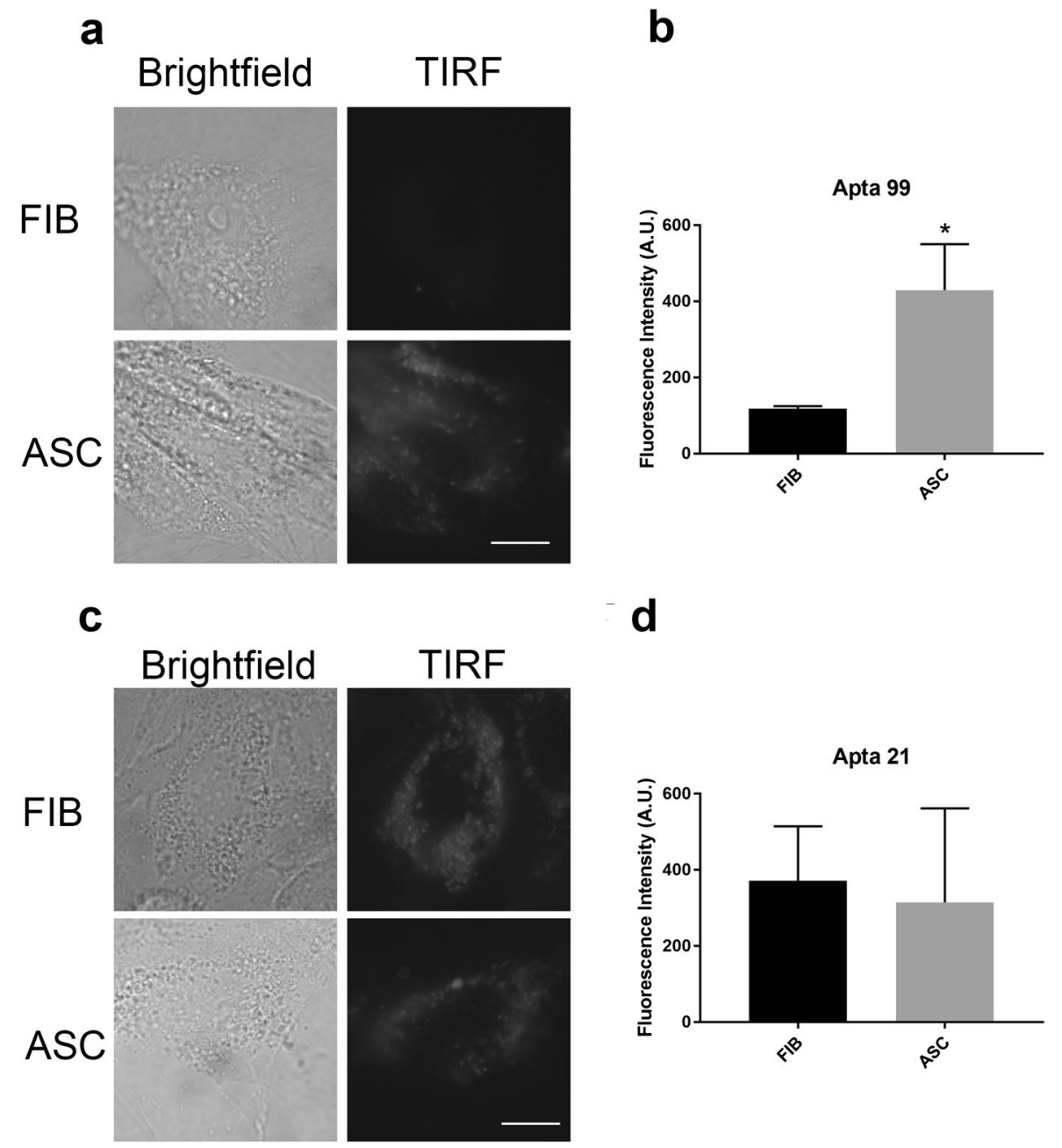

Supplementary figure 4

Publisher's Note Springer Nature remains neutral with regard to jurisdictional claims in published maps and institutional affiliations. 